\title{
Exploring reach and experiences of participation in health-promoting senior meetings in a municipality context
}

\author{
Eva-Britt Norberg ${ }^{1} \cdot$ Elisabeth Biberg ${ }^{1} \cdot$ Magnus Zingmark ${ }^{2,3}$ CD \\ Received: 18 July 2019 / Accepted: 20 November 2019 / Published online: 21 December 2019 \\ (C) The Author(s) 2019
}

\begin{abstract}
Aim To explore reach and experiences of participants during implementation of health-promoting meetings of seniors in a Swedish municipality context.

Subjects and methods A mixed-methods approach was used, including older people who were recruited consecutively and invited to participate as they applied for health care and/or home help services in the municipality. Inclusion criterion was allocation of "early" home-care services, e.g., meals on wheels, safety alarms. Health-care services were limited to persons applying for an outside walker. The intervention was multi-professional, e.g., occupational therapy and physiotherapy. Each session included a mix of short lectures and group discussions about, for example, the importance of engagement in meaningful activity, social contacts, and physical activity. Recruitment procedures were modified during the trial in order to enhance reach. The data collection included information on the flow of participants during recruitment and participation in the intervention, field notes covering the experience of implementing the intervention, a survey covering adherence to recruitment procedures, and qualitative interviews exploring the experience of participants.

Results Senior meetings were experienced as positive and strengthened the participants in dealing with health-related concerns. The identification of potential participants and recruitment were challenging, but as recruitment procedures were modified, a higher proportion of potential participants were reached. In all, there were 29 participants over the study period.

Conclusion For health-promoting meetings to enable community-dwelling older people to fulfill their potential by positively affecting health outcomes, recruitment procedures for optimizing reach is a critical feature.
\end{abstract}

Keywords Healthy ageing $\cdot$ Prevention $\cdot$ Recruitment $\cdot$ Feasibility $\cdot$ Implementation

\section{Introduction}

A range of health-promoting and preventive interventions have been shown to result in positive effects for older people (Vass et al. 2005; Gustafsson et al. 2013; Rasinaho et al. 2012; Zingmark et al. 2014). If implemented, such interventions can promote health and well-being and thereby affect the expected increase in costs for health and social care (Ministry of Health

Magnus Zingmark

magnus.zingmark@ostersund.se

1 Department of Community Medicine and Rehabilitation, Division of Occupational Therapy, Umeå University, Umeå, Sweden

2 Department of Epidemiology and Public Health, Umeå University, Umeå, Sweden

3 Municipality of Östersund, Health and Social Care Administration, Östersund, Sweden and Social Affairs 2010; Zingmark et al. 2016). Therefore, municipalities should consider implementing health promotion for community-dwelling older people. However, there is no consensus on precisely what type of health promotion and/ or preventive interventions to implement. In addition, the translation of evidence gained in controlled trials into clinical practice has proved challenging (Glasgow et al. 2003). Therefore, more knowledge is needed on the process of implementing health promotion for older people in municipality practices.

The focus of this paper is on health-promoting meetings for seniors; an intervention including group sessions led by registered professionals, focusing on health-related topics such as engagement in daily activities, physical activity, and healthy eating, and aiming to support participants in increasing their control over factors contributing to health and well-being. Recent trials have shown that health-promoting senior meetings result in better outcomes on activities of daily living 
(ADL) (Gustafsson et al. 2013; Zingmark et al. 2014), leisure engagement (Zingmark et al. 2014), self-rated health (Zingmark et al. 2014), and physical function (Zidén et al. 2014), compared to no intervention. In addition, groupbased interventions seem to be more effective than individual approaches (Gustafsson et al. 2012; Zingmark et al. 2016). These trials have adopted a single-professional (Zingmark et al. 2014) or a multi-professional (Gustafsson et al. 2012) design, including one (Zingmark et al. 2014), four (Gustafsson et al. 2013) or eight (Zingmark et al. 2014) sessions, all leading to positive effects. In a cost-effectiveness analysis, including two different group-based interventions, one individual intervention and a control group, a onesession discussion group was identified as the most costeffective intervention (Zingmark 2015). Thus, senior meetings including one or a few sessions seem to be an efficient format of delivering health promotion for community-dwelling older people.

Despite promising evidence, reaching the intended target group is a critical feature when implementing health promotion (Glasgow et al. 1999). In recent trials including independent, community-dwelling older people, approximately twothirds of the persons eligible declined to participate due to lack of interest, lack of time, or due to poor health (Gustafsson et al. 2012; Zingmark et al. 2014). As indicated by these trials, reaching the target group was challenging, and therefore the process of identifying and recruiting potential participants needs to be explored. Criteria for identifying potential participants should be both relevant and feasible to implement in ordinary practices. From the perspective of clinical routines within a municipality, persons seeking early home-care services could be a suitable target group for health-promoting interventions, since this could be seen as a first official sign of functional decline, and those seeking such help are easily identified in clinic. Restrictions in performing ADL are associated with future functional decline (Gill et al. 2003), and becoming dependent on home care has a negative impact on life satisfaction (Johannesen et al. 2004; Ottenvall Hammar et al. 2016). An additional risk factor for future decline in functioning is limitations in mobility (Hirsch et al. 2012). Thus, also persons seeking help in relation to mobility limitations could be easily identified, and be a relevant target group for health promotion.

The purpose of this study was to explore reach and experiences of the participants during implementation of healthpromoting senior meetings in a Swedish municipality context.

\section{Methods}

To address the purpose of the study, a mixed methods approach was applied (Polit and Beck 2004). Reach was explored by ongoing data collection during recruitment of participants, field notes, and the use of a web-based survey. The experiences of participants was explored by qualitative interviews.

\section{Context}

The study was conducted in 2015-2017 in a middlesized Swedish municipality. No specific healthpromoting intervention for older people was included as part of ordinary services in the municipality. Ordinary services were mainly focused on the provision of social care and home health care for persons with extensive needs for support in daily living. In order to initiate health promotion in the actual municipality, senior meetings were identified as a relevant intervention. A program for health-promoting senior meetings had been developed locally based on principles for participatory action research (PAR) (Taylor et al. 2004). The PAR process included a series of meetings with representatives of (i) the target group and (ii) professionals who would be involved in recruitment of participants or the implementation of the program (i.e., occupational therapists, physiotherapists, social workers, and district nurses). The focus was on (a) identifying a suitable target group for the intervention, (b) developing recruitment procedures, and (c) developing a program for the intervention. The process of developing, implementing, and evaluating the program was financed by a social investment fund in the municipality, and constituted a part of the long-term plan by the health and social care administrations to broaden existing ordinary services towards more health promotion and prevention. The third author of this paper was responsible for development of the program, coordination of the sessions, and the study procedures.

Guided by a literature review conducted by the last author and discussions with both groups of representatives, the target group for the intervention was identified as persons 65 years or older who met either of the following criteria: (i) applicant for "early" home help services, e.g., help with cleaning, shopping, food delivery and safety alarms, or (ii) applicant for outside walker. Three exclusion criteria for the program were selected based on ethical and practical grounds: (a) need for help with basic activities of daily living (e.g., dressing, bathing), (b) apparent cognitive or communication problems, or (c) terminal disease.

\section{Recruitment}

During the project, the routine for recruitment was modified as a result of the knowledge gained. At the start of the project 
(phase 1), social workers and physiotherapists were key professionals in identifying potential participants in their roles as meeting persons applying for (i) early home-help services or (ii) outside walkers. During two ordinary staff meetings, before and during the project, information about the project was provided and the staff were given opportunities to ask questions. In addition, written information about the project and their role in the recruitment process was sent by e-mail. Over time, monthly e-mail reminders about the study were sent out to the involved professionals. In all, 19 social workers and nine physiotherapists were involved in the process of identifying potential participants.

At first contact with a social worker or a physiotherapist, potential participants were informed about the healthpromoting senior meetings. For those who were identified as potential participants and willing to receive more information, the social worker or physiotherapist informed the project coordinator (last author). Within 2 weeks, the project coordinator contacted potential participants by telephone and provided more information about the senior meetings and the research study. Participants were recruited and invited to the senior meetings consecutively.

During phase 2, participants were identified by the last author from clinical records as follows; (i) retrospectively for each month during a 3-month period, all new decisions on social care were abstracted, (ii) based on in- and exclusion criteria, all potential participants were identified. Information about the senior meetings and the research study was provided in the same way as during phase 1 .

\section{Intervention}

The senior meetings were organized at a senior center located in the city center. The program consisted of two group meetings, held by an occupational therapist and a physiotherapist. After the first groups had been conducted, a dietitian and a district nurse were also involved in one senior meeting each. Each senior meeting lasted $2 \mathrm{~h}$ and included lectures, movies, and discussions related to activity, participation, and health, with a short coffee break. The lectures included PowerPoint slides, and were held in an informal manner. The role of the group leaders was to support participants to engage in discussions, to acknowledge the participants' experiences, and to facilitate exchange of knowledge among participants rather than being an expert (Johansson et al. 2014). The content of the intervention is summarized in Table 1.

The participants were given leaflets covering the topics of physical exercise, healthy eating for older people, and activities available for seniors in the municipality, and how to seek social support and health care. To participants who did not attend the meetings, leaflets were sent by mail.
Table 1 Topics covered during the senior meetings

\begin{tabular}{ll}
\hline Topics & Profession \\
\hline Engagement in meaningful activity & OT/PT \\
Managing daily life & OT \\
Digital opportunities and challenges & OT \\
Housing accessibility & OT \\
Physical activity - theory and practical exercises & PT \\
Healthy eating & D/PT \\
Health care contacts & DT/PT \\
Available societal support & OT/PT \\
\hline
\end{tabular}

$O T$ occupational therapist, $P T$ physiotherapist, $D T$ district nurse, $D$ dietitian

\section{Data collection and analyses}

Throughout the study, quantitative and qualitative data were collected in order to explore reach and the experiences of participants.

\section{Reach}

Data was collected on the number of persons identified, contacted, and declining or agreeing to participate. Reach, expressed in percentages, was calculated as the number of persons participating in at least one senior meeting divided by the total number of persons in the estimated population. Before the trial, dialogues with social workers and physiotherapists indicated that the number of potential participants each year was approximately 240 persons who were granted early home help and 30 persons who were granted an outside walker. Thus, in all, the estimated population was 270 persons per year.

To explore recruitment procedures and the roles of those involved in recruitment, a Web-based survey was used in March 2017. The survey included questions related to awareness of and knowledge about the senior meetings, and the role each professional had in recruitment. In all, the survey was distributed to 19 social workers and nine physiotherapists involved in recruitment. In addition to the survey, field notes were kept, including summaries from staff meetings with social workers and physiotherapists.

\section{Experiences of the participants}

An empirical, qualitative study design, with an inductive character, was chosen to explore the experience of participants. Data were collected by qualitative interviews by telephone following a semi-structured interview guide developed by the second author. The questions focused on how the participants had experienced participating in the senior meetings. In all, nine participants during phase 1 were recruited 
consecutively for the interviews, and each person was interviewed twice. The age of participants ranged from 79 to 89 years, and six participants were women. The first nine interviews were conducted 1 week after the first senior meeting carried out by the second author. The nine follow-up interviews were conducted after completion of the program by an experienced occupational therapist, whether the participants took part in the second meeting or not. The interviews lasted on average $22 \mathrm{~min}$, with a maximum of $40 \mathrm{~min}$, and were recorded and transcribed verbatim.

The transcribed interviews were analyzed according to qualitative content analysis (Graneheim and Lundman 2004), including a focus on both the subject and the context, comparing of similarities and differences with regard to the phenomena studied. The analysis was conducted by the three authors in cooperation. First the interviews were read through several times to gain an understanding of the whole (EB initials of author). Second, content relating to the aim and meaning units were independently identified and discussed (EB, EBN initials of author). In the third step, these meaning units were abstracted and labelled with a code (EB, EBN initials of author). In the fourth step, codes with a mutual meaning were grouped together and abstracted into sub-themes and themes (EB, EBN, MZ initials of author). In order to increase the trustworthiness of the analysis, the three authors compared codes, sub-themes, and themes with the interviews, and discussed any differences of opinion until an agreement was reached.

\section{Results}

The results are presented under two headings; reach (including recruitment and flow of participants) and experiences of the participants.

\section{Reach}

During the project, the routine for recruitment was modified as a result of the knowledge gained. Therefore, reach is presented in relation to the two phases of the project: phase 1, during which participants were identified by social workers and physiotherapists, and phase 2, during which participants were identified from clinical records. Reach in relation to both phases is presented in Table 2.

During the first phase, from January 2016 to April 2017, 40 potential participants were identified and recruited consecutively by social workers $(n=15)$ and physiotherapists $(n=$ $25)$. The mean age was 79.9 years (60-91 years) and 25 were women $(62.5 \%)$. Thirty-eight persons were contacted by telephone and provided with information about the senior meetings. The flow of participants is shown in Fig. 1. Senior meetings were held consequtively, including four groups for the first senior meeting and three groups for the second meeting. Initially, six participants were invited to participate in each senior meeting. However, last-minute cancellations during the first two meetings resulted in few participants (e.g., a minimum of two), and therefore ten participants were invited to subsequent meetings to ensure a sufficient number of participants.

In relation to pre-trial estimates, i.e., 270 persons/year times 1 year and 4 months (January 2016-April 2017), few potential participants $(40 / 359=11.1 \%)$ were identified during phase 1 . Reach as calculated for those who participated on at least one senior meeting in relation to the estimated total population was $5.8 \%$.

The recruitment rate was lower than expected, and in combination with late drop-outs (e.g., due to illness) the planning and the implementation of the senior meetings was challenging.

The Web-based survey was answered by 14 out of 19 social workers and seven out of nine physiotherapists. Out of these, 16 stated that they were somewhat familiar with the program, the content of the program, and which the intended target group was. Of the 16 who were familiar with the programme, 13 thought that the program addressed a relevant need, three did not. Twelve professionals knew their task in the recruitment process; nine stated that they were not sure. Ten respondents answered that they had not informed or met anyone who could be a potential participant about the possibility of them participating; 11 answered that they had informed some of the potential participants. No respondent answered that all potential participants had been informed about the project. Ten professionals experienced problems with informing and recruiting

Table 2 Reach in relation to the estimated population during phase 1 (16 months) and phase 2 ( 3 months)

\begin{tabular}{lcc}
\hline & Phase 1:n(\%) & Phase 2:n(\%) \\
\hline Estimated population & $359(100)$ & $59(100)$ \\
Potential participants identified & $40(11)$ & $59(100)$ \\
Agreed to participate & $29(8)$ & $8(14)$ \\
Reach, i.e., participated in at least one senior meeting & $21(6)$ & $8(14)$ \\
\hline
\end{tabular}


Fig. 1 Recruitment during the first phase, covering a period of 16 months

\section{PHASE 1}

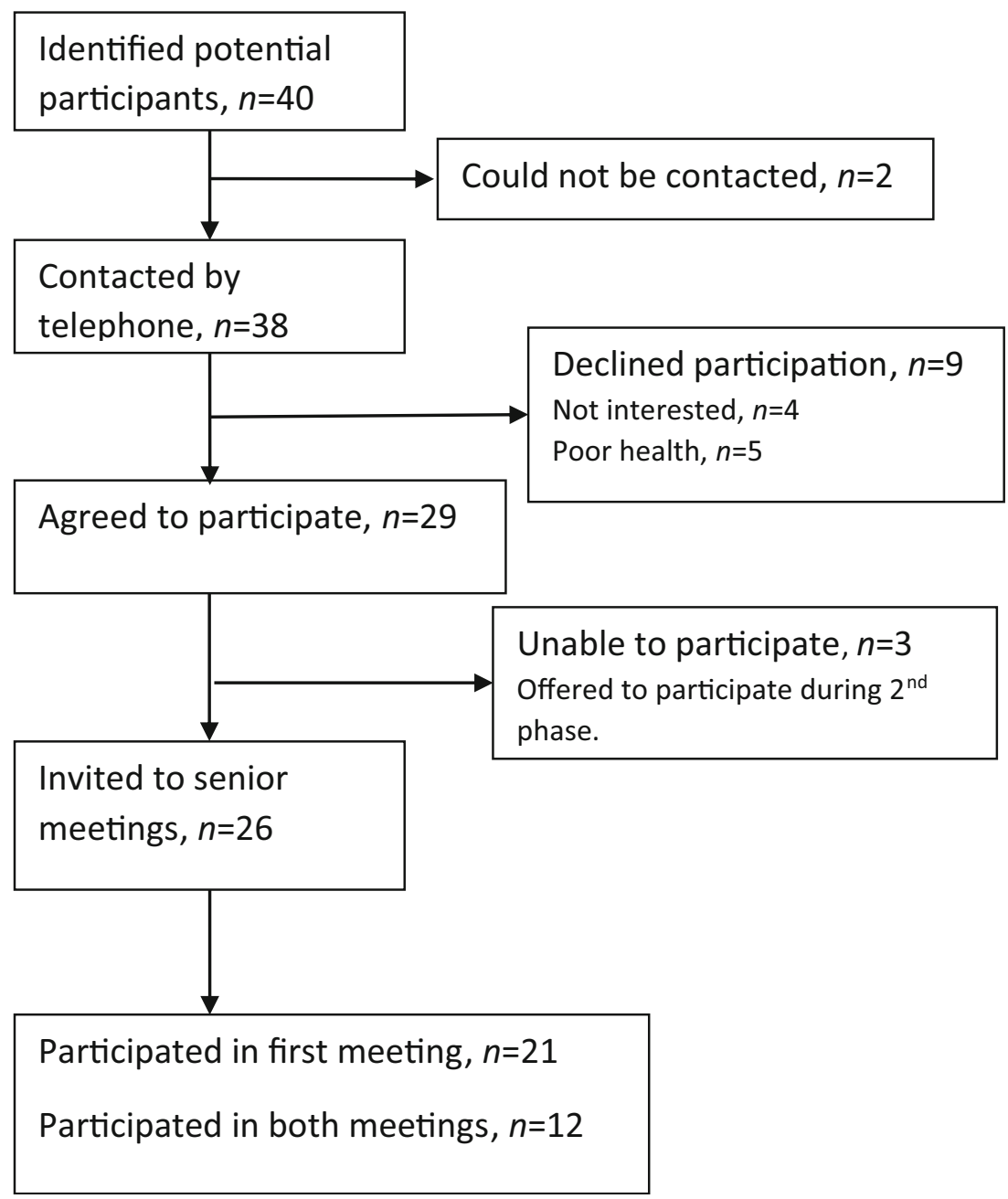

participants. One reason was that during initial contacts with persons applying for help from the municipality, there was a lot of information that needed to be provided to the person, and the information about senior meetings was easy to forget or not prioritized. Another problem was that it was not often they met potential participants and therefore it could be easy to forget. Similar information was also identified from field notes from the staff meetings.

During the second phase, recruitment only included persons meeting the first inclusion criterion of early home-help services, thus an estimated population of 240 persons per year. Building on the knowledge gained during the first phase, and aiming to address the logistical challenges, the routines for recruitment were modified. The modified routine for recruitment was based on data extracted from clinical records covering a period of 3 months (August-October 2017). From a list of all persons who had been granted some kind of social services, and screening for in/exclusion criteria, potential participants were identified and subsequently contacted by telephone, Fig. 2 .

The results of using the new method for identifying potential participants indicated that pre-trial estimates were reliable, i.e., 59 potential participants were identified during 3 months. While all potential participants were identified, $72.9 \%$ could be contacted by telephone and $13.6 \%$ agreed to participate. Including the three persons who could not participate during the first phase, invitations to participate in a first senior meeting were sent to 11 persons. Distributed over two senior meetings including five participants each, reach as calculated for those who participated in at least one senior meeting in relation to the estimated total population during phase two was $13.6 \%$ (N.B. based on the eight persons identified during phase 2). 
Fig. 2 Recruitment during the second phase, covering a period of 3 months

\section{PHASE 2}

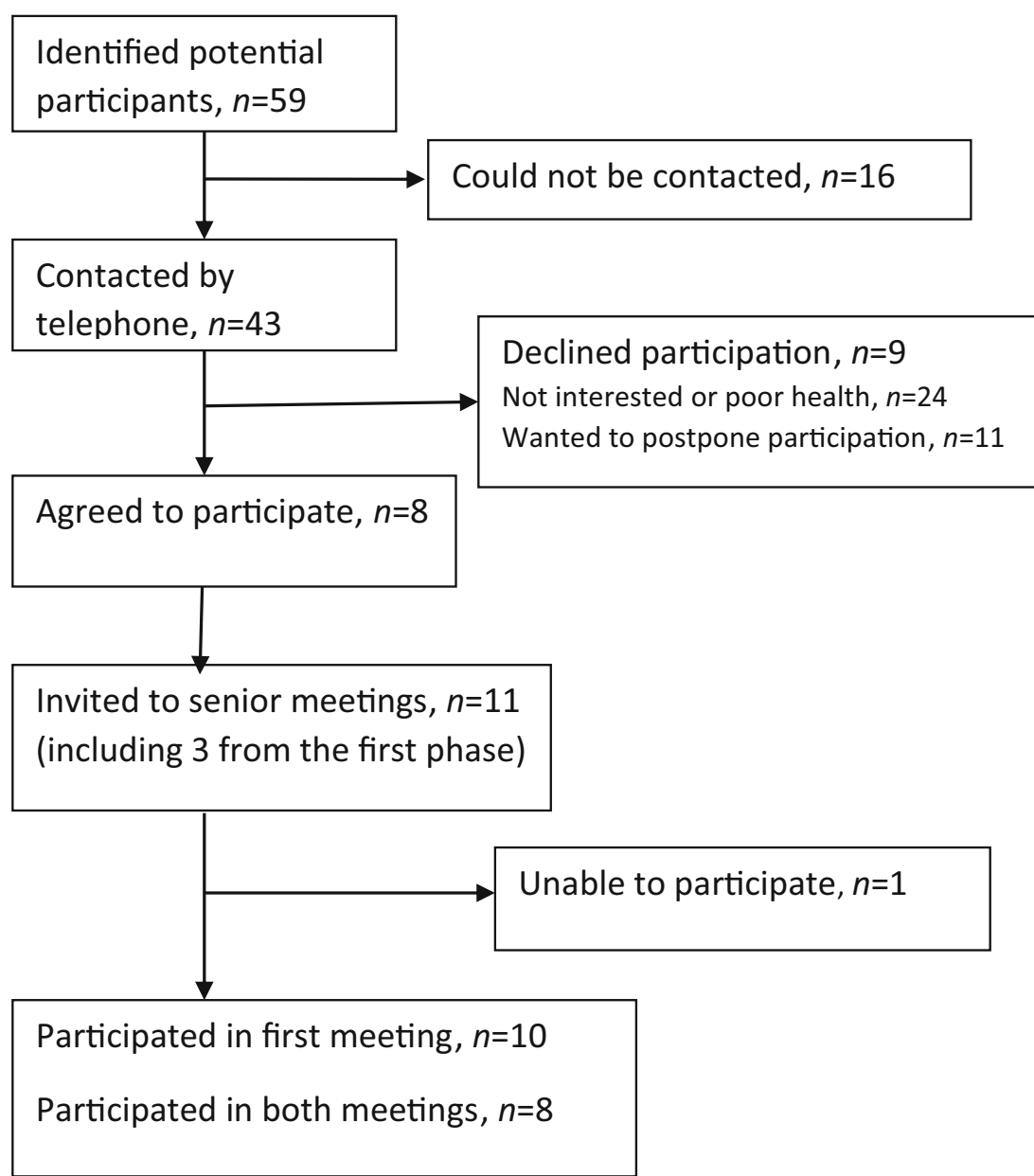

\section{Experiences of the participants}

In the analysis, three themes and five subthemes were identified (Table 3). They are presented below and illustrated with quotations from the interviews.

\section{Expectations and practicalities enable participation}

The participants described factors that motivated them to participate in the senior meetings, but also factors that restricted or made participation complicated.

Table 3 Sub-themes and themes in the analysis of the participant's experiences of participation during the implementation of a health promotion senior meetings

$\begin{array}{ll}\text { Sub-themes } & \text { Themes }\end{array}$

Curiosity motivates

Transportation, site and time affect participation

Information and practice are appreciated

Group size matters for discussion and interaction

An eye-opener motivates change

Already satisfied with my lifestyle
Expectations and practicalities enable participation

The content and group constellation matters

Inspiration and confirmation may affect everyday life 


\section{Curiosity motivates}

To participate was seen as an opportunity to gain new knowledge, meet other people in a similar situation, and to feel less alone. Initially, they did not know precisely what the content of the meetings would be, and a clear invitation both by phone and by a letter to clarify this was proposed. The participants described a mixed sense of curiosity and uncertainty:

"Unaccustomed things are a bit frightening, so I was worried before I got there. But it went just fine when I finally got there."

\section{Transportation, site, and time affect participation}

Transportation to and from the meeting site was experienced as somewhat problematic for those who travelled by car (e.g., difficulties in finding a vacant parking lot) and those travelling by bus, (e.g., poor fit between the time table for the bus and the time of the senior meetings):

"Getting home is a problem because of my bus .. // .. So I was a bit concerned. We stopped after half-past three, and the last bus is quarter past three."

Some participants also described that they were unable to walk the distance from the nearest bus stop. In all, these factors made participation complicated.

\section{The content and group constellation matters}

The actual content and how the senior meetings were conducted were described as important, both with regard to what the participants learned from the meetings, but also how they experienced the actual participation in the meetings.

\section{Information and practice were appreciated}

Overall, the participants appreciated the concept, and experienced participation as fun. The information provided during the meetings was described in favourable terms as important, detailed, and easily accessible. The participants reported that they could raise concerns and receive answers, and felt that the leaders "tied up loose ends". In all, they expressed that it was a good program that touched essential areas of everyday life to which they could relate:

"Because I think this covers just about everything that is. There are both health and balance and how to get in touch with various agencies within the community and all that."
Participants highlighted the topic of physical activity in positive terms. Even though they were aware of much of the information provided, they considered it to be a useful remainder and deepened their knowledge. For example, in relation to physical exercises, they thought it was good to learn how to perform the exercises correctly. Another topic that was experienced as relevant was how the home environment could be adjusted in order to reduce fall risks or to enhance accessibility in the kitchen.

The participants appreciated the information shown on PowerPoint slides because it reinforced what was discussed. Also the information leaflets about, for example, healthy eating, food preparation, and physical exercise were considered useful, since those areas were experienced as necessary in their daily life. The leaflets served as a reminder of the information when they went home:

"Yes, it was good, I think. Indeed it was. Because we got to do some gymnastics and stuff like that. And we got some papers on food and things like that. And it was very good I think."

Not attending the meeting but being provided with information by mail could be somewhat problematic, as one participant described:

"It says computer and internet, and about the participation or digital divide, I do not know what they mean, and social contacts through the senior pages .. //.. senior pages, what is that? Is there anything that the municipality provides?"

Although the participants were satisfied with the meeting overall, they emphasised that they lacked information about how to get in contact with health services because they found it difficult to call the different health-care services.

\section{Group size mattered for discussions and interaction}

Conflicting events, e.g., healthcare contacts, family matters, or sudden illness restricted some persons from participating in the second meeting. These drop-outs led to a bit of disappointment for those attending, since a reduced number of participants affected the dynamics in the meetings:

"Yes, I thought there would be a few more people there. But I did get some good opinions and knowledge there."

However, when in a smaller group, participants expressed that they felt safe talking and described that 
they could learn from other participants by listening and sharing advice. Preferably, a suitable group size seemed to be four to six persons, as additional participants in each session added more experiences and opinions to the group discussions.

Some participants experienced that they mostly had listened to the group leaders during the meetings, and that the discussions were short and superficial due to lack of time. In contrast, other participants experienced that the discussions had been important, that it had been valuable to listen to the other participants' experiences and to realize that they were not alone in their situation. But this could also result in a sense of exclusion:

"I've have been fortunate, I have been so healthy through my life. So I do not know if I was really appropriate for that group."

\section{Inspiration and confirmation may affect everyday life}

This theme describes experiences of how participation in the senior meetings had influenced the everyday life of the participants.

\section{An eye-opener motivates change}

Some participants reported that they experienced participation as an eye-opener providing new perspectives. While usually being caught up in daily routines, participation led to new initiatives. The material provided was seen as a help to remember and engage in more activity, e.g., to become inspired to contact a physiotherapist in order to talk about and try out some exercises. One participant described how the information about food had affected and contributed to her eating habits:

\section{"I've never eaten so much as they showed, that eating with snacks. I have eaten breakfast, lunch, and dinner. Now I have tried to take a little snack in the evening. So I do not have an empty stomach when I go to sleep."}

Even before the senior meetings, most participants were already receiving assistance from others, e.g., mowing the lawn, changing light bulbs, cleaning windows, and using security alarms. But for some, the senior meetings was an inspiration to change:

"Yes, I have thought about how hard it is to clean the floor. My wife has back pain so she can't clean it, so I have to do it, so maybe we would need help."

\section{Already satisfied with my lifestyle}

Some participants considered the information provided and topics discussed as rather obvious, as they already saw themselves as socially and physically active:

"-Well I can tell you that I am already busy making healthy choices all the time. It comes naturally to me. I mean, I am mobile and do things all the time, so maybe those themes weren't so relevant for me.."

A topic that most participants did not think they had changed after the meetings was their use of new technology and the Internet. All of the participants already used smartphones daily, and some of them used the computer to pay bills and to use social networks such as Facebook, while others received help from their relatives, for example to order train tickets.

\section{Discussion}

The results presented in this paper provide hands-on knowledge relevant for translating evidence on health promotion for older people from controlled trials into ordinary practice in a Swedish municipality. Even though the existing evidence clearly supports the idea that a short-term health-promoting intervention is likely to result in a range of health benefits for the individual and a cost-efficient use of resources, the logistical challenges may be substantial.

Reach was low, and only a small proportion of potential participants were actually identified and reached during the first phase of the project. Clearly, recruitment procedures were not effective. A possible explanation to the low recruitment rate could be a combination of an insufficient understanding among professionals involved in recruitment, of the need the intervention was intended to address, and of a lack of compliance to recruitment procedures. Information provided during staff meetings and reminders sent by e-mail to involved professionals were apparently not sufficient to ensure that all potential participants were identified. The implementation of health promoting senior meetings was a new initiative in the municipality, and a framework that can help us understand to what extent an organization is prepared to initiate such change is the community readiness model (Oetting et al. 1995). Even though no formal assessment of the municipality's actual stage of readiness was conducted, the results indicate that in relation to health promotion, the municipality's readiness was oriented towards the earlier phases described in the framework. In order to move forward towards enhancing readiness to implement health-promoting initiatives, some strategies could be helpful. These strategies include different modes of informing the community to raise awareness of the issue, e.g., by 
newsletters, media, and meetings, by conducting local surveys to increase knowledge, or by conducting focus groups to discuss issues and identify strategies (Edwards et al. 2000). Specifically in relation to senior meetings and the involved professionals, our results indicate that further information would be needed in order to improve compliance to the recruitment procedures first used.

Another perspective on the feasibility of recruitment strategies concerns the optimal timing of informing and identifying potential participants. Given that the main reason for the contact between the person and the social worker or physiotherapists is related to other issues, the timing for also introducing senior meetings might have been inappropriate. The results indicated that this might have been the case, and therefore the alternative recruitment strategy was developed and tested during the second phase. The modified strategy used to identify potential participants was successful, and confirmed the pre-trial estimate of the number of potential participants. However, upon contact, only a small proportion were willing to participate. Based on the data collected, there is no clear explanation for this but clearly, when all potential participants actually can be identified, additional efforts are still needed to enhance recruitment rates and reach.

The results from interviewing the participants can provide some guidance on how the information could be improved in order to enhance reach. When being invited to participate, some participants described somewhat conflicting thoughts between curiosity when facing a new experience and the uncertainty of meeting new people and not knowing exactly what to expect. Both these concerns could be addressed by presenting information about the senior meetings using different modes of communication, e.g., by telephone and through written information by mail. Given that many participants stated that they used smartphones, the use of e-communication could be considered as a complement.

The results showed that although the participants did not experience the information in the senior meetings as new, it was still appreciated. By meeting others in similar life situations, being provided with information, trying out exercises, and discussing everyday matters and challenges, the participants became inspired to take action in their everyday life. Our results are in line with previous studies in the field showing that participation in senior meetings can be a "key to action" (Behm et al. 2013) leading to positive health outcomes in both the short term and long term (Gustafsson et al. 2013; Gustafsson et al. 2012; Zidén et al. 2014). However, some participants considered themselves to be too healthy to participate in the senior meetings, indicating a need to further explore the match between the intervention and the intended population. In previous health-promoting trials, as many as $75-94 \%$ of those who declined to participate did so due to a lack of interest or time (Dahlin-Ivanoff et al. 2010; Zingmark et al. 2014). Therefore, the issue of designing an intervention that truly matches the intended population remains. While the focus for this study was healthpromoting senior meetings, also other formats of health promotion could be considered. For those who do not consider a group format to be interesting, other formats may be more appropriate. Even though we argue that senior meetings seem to be an intervention format that yields a broad range of positive effects and has proven to be cost effective, preventive home visits and physical activity counselling are interventions delivered in an individual format that also have shown positive effects (Sahlen et al. 2008; Rasinaho et al. 2012). Instead of thinking how to identify the (one) most optimal format of health promotion, a more relevant question could be how to identify an optimal mix of interventions that attracts a high proportion of potential participants, thus increasing reach.

The results indicate that the design of the intervention seems to be feasible, but that some features need to be highlighted since they can be improved. While an indoor environment that is accessible is important, also the outdoor environment needs to be considered, including access to parking and transportation by bus.

\section{Methodological considerations}

Overall, the mixed-methods approach used to collect data over time provided new hands-on knowledge in relation to implementation of health promotion in a municipality context. However, data were limited to a relatively small sample, and even though the results can provide some guidance to implementation, ongoing evaluation of participants' experiences, reach, and effects will be needed to determine the benefits of health-promoting senior meetings in ordinary clinics. The experience of the professionals involved in identification and recruitment of participants during the first phase was evaluated by a survey and complemented with field notes from staff meetings. In order to gain a deeper understanding, e.g., in relation to readiness for change and compliance to recruitment procedures, interviews could have added valuable information. The first and second authors were external in relation to the organization in which the senior meetings were implemented, a fact that strengthens the validity of the qualitative findings. The qualitative data were only collected during the first phase, and the lack of such data from the second phase is a limitation. However, the 
findings were similar to those found in previous trials related to health-promoting senior meetings.

\section{Conclusion}

The identification and recruitment of potential participants were challenging features during implementation of health-promoting senior meetings in a municipality setting. By using clinical records, substantially more potential participants were identified compared to when firstline professionals were instructed to identify persons. However, recruitment rates and reach remained low. Overall, participants experienced participation as positive, and some qualitative findings indicated how recruitment rates and reach could be improved. Clear information that stimulates curiosity and encourages participation seem to be factors that could attract potential participants who were somewhat hesitant. When participating, the group format under professional guidance is experienced as stimulating, but also requires that the group size is sufficiently large.

Acknowledgements The authors wish to thank all persons involved in the process of developing and implementing the program, and the informants who shared their experiences during the qualitative interviews. Finally, we would like to thank Johanna Morin for conducting the second round of interviews.

Funding Information Open access funding provided by Umea University.

\section{Compliance with ethical standards}

Ethics Participants in the study were given written and verbal information about the study, and informed of their right to decline participation at any time without consequences to their rights and access to other societal services. The study was approved by the Ethical Board at Umea University, Dnr: 2015/268-31Ö.

Conflict of interest The authors declare that they have no conflict of interest.

Open Access This article is licensed under a Creative Commons Attribution 4.0 International License, which permits use, sharing, adaptation, distribution and reproduction in any medium or format, as long as you give appropriate credit to the original author(s) and the source, provide a link to the Creative Commons licence, and indicate if changes were made. The images or other third party material in this article are included in the article's Creative Commons licence, unless indicated otherwise in a credit line to the material. If material is not included in the article's Creative Commons licence and your intended use is not permitted by statutory regulation or exceeds the permitted use, you will need to obtain permission directly from the copyright holder. To view a copy of this licence, visit http://creativecommons.org/licenses/by/4.0/.

\section{References}

Behm L, Zidén L, Dunér A, Falk K, Dahlin-Ivanoff S (2013) Multiprofessional and multi-dimensional group education - a key to action in elderly persons. Disabil Rehabil 35(5):427-435. https:// doi.org/10.3109/09638288.2012.697249

Dahlin-Ivanoff S, Gosman-Hedström G, Edberg AK, Wilhelmson K, Eklund K, Duner A, Ziden L, Welmer AK, Landahl S (2010) Elderly persons in the risk zone. Design of a multidimensional, health-promoting, randomised three-armed controlled trial for "prefrail" people of 80+ years living at home. BMC Geriatr 10:27. https://doi.org/10.1186/1471-2318-10-27

Edwards RW, Jumper-Thurman P, Plested BA, Oetting ER, Swanson L (2000) Community readiness: research to practice. J Community Psychol 28(3):291-307

Gill TM, Allore H, Guo Z (2003) Restricted activity and functional decline among community-living older persons. Arch Intern Med 163(11):1317-1322. https://doi.org/10.1001/archinte.163.11.1317

Glasgow RE, Vogt TM, Boles SM (1999) Evaluating the public health impact of health promotion interventions: the RE-AIM framework. Am J Pub Health 89(9):1322-1327

Glasgow RE, Lichtenstein E, Marcus AC (2003) Why don't we see more translation of health promotion research to practice? Rethinking the efficacy-to-effectiveness transition. Am J Public Health 93(8):12611267

Graneheim UH, Lundman B (2004) Qualitative content analysis in nursing research: concepts, procedures and measures to achieve trustworthiness. Nurse Educ Today 24(2):105-112. https://doi.org/10. 1016/j.nedt.2003.10.001

Gustafsson S, Wilhelmson K, Eklund K, Gosman-Hedström G, Zidén L, Kronlöf GH, Højgaard B, Slinde F, Rothenberg E, Landahl S, Dahlin-Ivanoff S (2012) Health-promoting interventions for persons aged 80 and older are successful in the short term-results from the randomized and three-armed elderly persons in the Risk Zone study. J Am Geriatr Soc 60(3):447-454. https://doi.org/10.1111/j.15325415.2011.03861.x

Gustafsson S, Eklund K, Wilhelmson K, Edberg A-K, Johansson B, Kronlöf GH, Gosman-Hedström G, Dahlin-Ivanoff S (2013) Long-term outcome for ADL following the health-promoting RCT-elderly persons in the risk zone. Gerontologist 53(4):654663. https://doi.org/10.1093/geront/gns121

Hirsch CH, Buzková P, Robbins JA, Patel KV, Newman AB (2012) Predicting late-life disability and death by the rate of decline in physical performance measures. Age Ageing 41(2):155-161. https://doi.org/10.1093/ageing/afr151

Johannesen A, Petersen J, Avlund K (2004) Satisfaction in everyday life for frail 85-year-old adults: a Danish population study. Scand J Occup Ther 11(1):3-11

Johansson E, Borell L, Jonsson H (2014) Letting go of an old habit: group leaders' experiences of a client-centred multidisciplinary fallsprevention programme. Scand J Occup Ther 21(2):98-106. https:// doi.org/10.3109/11038128.2013.868515

Ministry of Health and Social Affairs (2010) Den ljusnande framtid är vård. https://www.regeringen.se/rapporter/2010/06/s2010.021/. Accessed 20190409

Oetting ER, Donnermeyer JF, Plested BA, Edwards RW, Kelly K, Beauvais F (1995) Assessing community readiness for prevention. Int J Addict 30(6):659-683. https://doi.org/10.3109/ 10826089509048752

Ottenvall Hammar I, Dahlin-Ivanoff S, Wilhelmson K, Eklund K (2016) Self-determination among community-dwelling older persons: explanatory factors. Scand J Occup Ther 23(3):198-206. https://doi. org/10.3109/11038128.2015.1126348

Polit DF, Beck CT (2004) Nursing research: principles and methods. Lippincott Williams \& Wilkins, Philadelphia 
Rasinaho M, Hirvensalo M, Törmäkangas T, Leinonen R, Lintunen T, Rantanen T (2012) Effect of physical activity counseling on physical activity of older people in Finland (ISRCTN 07330512). Health Promot Int 27(4):463-474. https://doi.org/10.1093/heapro/dar057

Sahlen KG, Löfgren C, Hellner BM, Lindholm L (2008) Preventive home visits to older people are cost-effective. Scand J Pub Health 36(3): 265-271. https://doi.org/10.1177/1403494807086983

Taylor RR, Braveman B, Hammel J (2004) Developing and evaluating community-based services through participatory action research: two case examples. Am J Occup Ther 58(1):73-82. https://doi.org/ 10.5014/ajot.58.1.73

Vass M, Avlund K, Lauridsen J, Hendriksen C (2005) Feasible model for prevention of functional decline in older people: municipality-randomized, controlled trial. J Am Geriatr Soc 53(4):563-568. https:// doi.org/10.1111/j.1532-5415.2005.53201.x

Zidén L, Häggblom-Kronlöf G, Gustafsson S, Lundin-Olsson L, DahlinIvanoff S (2014) Physical function and fear of falling 2 years after the health-promoting randomized controlled trial: elderly persons in the risk zone. Gerontologist 54(3):387-397. https://doi.org/10.1093/ geront/gnt078
Zingmark M (2015) Occupation-focused and occupation-based interventions for community-dwelling older people: Intervention effects in relation to facets of occupational engagement and cost effectiveness. Dissertation: http://www.diva-portal.org/smash/record.jsf?pid= diva2\%3A789740\&dswid=-3641. Accessed 20190409. Umeå University

Zingmark M, Fisher AG, Rocklöv J, Nilsson I (2014) Occupationfocused interventions for well older people: an exploratory randomized controlled trial. Scand J Occup Ther 21(6):447-457. https://doi. org/10.3109/11038128.2014.927919

Zingmark M, Nilsson I, Fisher AG, Lindholm L (2016) Occupationfocused health promotion for well older people-a costeffectiveness analysis. Br J Occup Ther 79(3):153-162. https://doi. org/10.1177/0308022615609623

Publisher's note Springer Nature remains neutral with regard to jurisdictional claims in published maps and institutional affiliations. 